\title{
RELAÇÃO ENTRE A MATRIZ LINGÚIISTICA MULTIMODAL E A ATENÇÃA CONJUNTA DE CRIANÇA COM SÍNDROME DE DOWN
}

\author{
Relationship between the multimodal linguistic matrix and \\ joint attention of child with Down syndrome
}

Resumo: A síndrome de Down (SD) é uma condição genética resultante da presença extra de um cromossomo 21, que pode gerar diversos problemas de saúde, como cardiopatias, e atraso no desenvolvimento da linguagem. As crianças com a síndrome apresentam mais déficits na linguagem expressiva, enquanto a sua compreensão e comunicação gestual é mais desenvolvida. Nesse sentido, este estudo objetivou analisar a relação entre as produções linguísticas e a atenção conjunta de uma criança com síndrome de Down em processo de intervenção fonoaudiológica. Trabalhou-se com a hipótese de que as produções linguísticas e a atenção conjunta se desenvolvem mutuamente. Para isso, foram realizadas filmagens semanais, durante um ano de atendimento fonoaudiológico de um menino com SD que possuía 16 meses no início da coleta e apresentava uma cardiopatia congênita. Posteriormente, os vídeos foram analisados no programa ELAN, a fim de descrever quantitativamente as produções vocais e gestuais, e a atenção conjunta da criança. Constatou-se que a intervenção fonoaudiológica favoreceu o desenvolvimento da linguagem da criança com síndrome de Down, principalmente das produções vocais $(p=0,04)$, e que houve um crescimento conjunto entre as produções gestuais $(p=0,001)$ e a atenção conjunta da criança. Desse modo, com o atraso no desenvolvimento da linguagem verbal, as produções gestuais da criança com SD favoreceram sua inserção em cenas de atenção conjunta.

Palavras-chave | Desenvolvimento da linguagem. Síndrome de Down. Matriz linguística multimodal. Atenção conjunta.

\author{
Ivonaldo Leidson Barbosa LIMA ${ }^{1}$ \\ Isabelle Cahino DELGADO ${ }^{2}$ \\ Marianne Carvalho Bezerra CAVALCANTE ${ }^{3}$
}

Abstract: The Down syndrome is a genetic condition resulting from the extra presence of a chromosome 21 , which can lead to various health problems such as heart disease and delay in language development. Children with the syndrome have more deficits in expressive language, while comprehension and gestural communication is more developed. Thus, this study aimed to analyze the relationship between language productions and joint attention of a child with Down syndrome in speech-language therapy process. We have worked with a hypothesis that linguistic productions and joint attention develop mutually. For this, the speech-language therapy of a boy with Down syndrome who was 16 months old at the beginning of the collection of the data and had a congenital heart defect was filmed weekly, for a year. Subsequently, the videos were analyzed in the ELAN program in order to quantitatively describe the vocal and gestural productions, and children's joint attention. It was found that the speechlanguage therapy favored the development of the child's language with Down syndrome, especially the vocal productions $(p=0.04)$, and that there was a mutual growth between gestural production $(p=0.001)$ and joint attention of the child. Thus, with the delay in the development of verbal language, the gestural productions of the child with DS favored its inclusion in joint attention scenes.

Keywords | Language development. Down syndrome. Multimodal linguistic matrix. Joint attention.

\footnotetext{
1 Lima. UFPB. Endereço eletrônico: ivonaldoleidson@gmail.com

2 Delgado. UFPB. Endereço eletrônico: fgaisabelle@hotmail.com

3 Cavalcante. UFPB. Endereço eletrônico: marianne.cavalcante@gmail.com
} 
- Relação entre a matriz linguística multimodal e a atenção conjunta de criança com síndrome de Down

\section{Introdução}

A aquisição da linguagem é um processo contínuo e sujeito a variações, que reflete a apropriação de uma língua pela criança. Os estudos nessa área podem ser voltados tanto ao processo de aquisição da linguagem de crianças consideradas com desenvolvimento típico (DT), quanto com alguma condição orgânica, social, educacional que possa interferir no desenvolvimento da criança (LIMA; CAVALCANTE, 2015).

Uma dessas condições é a síndrome de Down (SD), uma condição genética resultante da presença extra de um cromossomo 21 que se destaca por provocar alterações globais no processo de desenvolvimento da criança. Segundo Schwartzman (2003), a SD possui uma alta incidência na população (cerca de 1 para cada 800 indivíduos nascidos vivos) e pode afetar diferentes raças, etnias e classes socioeconômicas.

Diversos estudos apontaram que a SD provoca alteração no desenvolvimento da cognição e da linguagem das crianças, especialmente em relação à linguagem expressiva verbal, o que repercute na comunicação social. Segundo Freire et al. (2014, p. 253), as crianças com síndrome de Down "demonstram dificuldades no desenvolvimento de habilidades de comunicação mais sofisticadas, embora sua compreensão para vocabulário, gramática e sintaxe seja usualmente maior do que a sua habilidade expressiva sugere". Contudo, uma área bem desenvolvida nesses sujeitos é a compreensão verbal associada à expressão gestual (PORTO-CUNHA; LIMONGI, 2008; FERREIRA-VASQUES; ABRAMIDES; LAMÔNICA, 2017; LIMA; DELGADO; CAVALCANTE, 2017).

Tais crianças aprendem novas palavras e expandem seu vocabulário mais lentamente do que crianças com DT da linguagem e possuem dificuldades na fala, apresentando alterações sintáticas, fonológicas e articulatórias. Em contrapartida, as crianças com SD apresentam preferência pelo uso do meio gestual (ou a associação deste com a fala), que se torna um meio efetivo de interação e favorecerá o desenvolvimento da linguagem oral (LAWS; BISHOP, 2004; LIMONGI, 2010).

É importante considerar que a linguagem é sempre multimodal, pois gesto e fala são constitutivos de um único sistema linguístico; eles se encontram integrados numa mesma matriz de produção e significação (MCNEIL, 1985).

No processo de aquisição da linguagem, diferentes gestos e produções verbais são adquiridas e se aperfeiçoam mutuamente, em um contínuo, em contextos de interação e de atenção conjunta. Nesse sentido, surge o conceito de envelope ou matriz multimodal, que contempla a união, a mescla de três componentes da interação que emergem e 
se aperfeiçoam concomitantemente: o olhar, os gestos e as produções vocais (ÁVILANÓBREGA, 2010).

Um aspecto que tem suas origens no desenvolvimento infantil - atrelado ao entendimento pela criança do outro como agente intencional igual a ela própria - é a atenção conjunta, que representa interações sociais nas quais a criança e o adulto prestam conjuntamente atenção a uma terceira coisa, e à atenção um do outro à terceira coisa, por um período razoável de tempo (TOMASELLO, 2003).

A criança pode se inserir em três diferentes formatos de atenção conjunta durante seu desenvolvimento: a atenção de verificação, em que há um envolvimento conjunto entre o adulto e a criança, que divide sua atenção entre observar o adulto e verificar um dado objeto inserido no espaço; a atenção de acompanhamento, na qual a criança acompanha o olhar ou o gesto de apontar do adulto em direção a um objeto foco de atenção conjunta que será então o alvo da interação; e a atenção direta, em que ambos os sujeitos - adulto e criança - são responsáveis pela troca comunicativa caracterizada nesse contexto, que combina produções verbais (com frequente presença de itens linguísticos dêiticos) e não verbais, representada por gestos declarativos (os bebês esperam que o adulto compartilhe da atenção dada a tal objeto) e/ou imperativos (os bebês esperam que os adultos façam algo para eles), além do direcionamento feito através do olhar (TOMASELLO, 2003; COSTA FILHO; CAVALCANTE, 2013).

Com isso, as trocas comunicativas e o olhar entre os sujeitos atraem o foco do outro para o objeto ou evento, fundamentam a interação e funcionam como feedback durante o contexto de atenção conjunta. No processo de aquisição da linguagem não é diferente; as crianças, a partir do olhar, dos gestos e das produções verbais, se inserem nas cenas de atenção conjunta, em interlocução com o parceiro, e colaboram para o próprio aprimoramento das produções infantis.

Desse modo, este estudo objetivou analisar a relação entre as produções linguísticas e a atenção conjunta de uma criança com síndrome de Down em processo de intervenção fonoaudiológica. Trabalhou-se com a hipótese de que as produções linguísticas e a atenção conjunta se aprimoram mutuamente no desenvolvimento infantil.

\section{Métodos}

Este estudo foi avaliado e aprovado pelo Comitê de Ética em Pesquisa com Seres Humanos da instituição de origem, sob o parecer de $\mathrm{n}^{\circ}$ 1.360.357. Os responsáveis legais do participante da pesquisa assinaram o Termo de Consentimento Livre e Esclarecido, autorizando sua participação no estudo. 
- Relação entre a matriz linguística multimodal e a atenção conjunta de criança com síndrome de Down

A pesquisafoi desenvolvida em um projeto de extensãovinculado ao Departamento de Fonoaudiologia da instituição de origem, que tinha o objetivo de desenvolver ações de cunho fonoaudiológico junto a pessoas com síndrome de Down, a fim de beneficiar o desenvolvimento da linguagem, da aprendizagem e da interação.

Para isso, 49 pessoas com SD, na faixa etária de zero a 33 anos, frequentavam a intervenção semanalmente e eram atendidas individualmente ou em grupo durante uma sessão de 40 minutos, por dois alunos graduandos em Fonoaudiologia, supervisionados por fonoaudiólogos professores ou colaboradores.

A criança com SD analisada neste estudo é do sexo masculino, possuía 16 meses no início do processo de intervenção fonoaudiológica e sua família é constituída por pai, mãe, um irmão gemelar sem síndrome de Down e uma irmã com nove anos de idade.

Os procedimentos de coleta de dados podem ser divididos em três etapas:

- Avaliação - foi realizada uma entrevista inicial com os pais para coletar informações sobre a criança, principalmente acerca do desenvolvimento global e linguístico dela, e a avaliação da criança com SD;

- Terapia - os extensionistas planejaram estratégias para a atuação junto às crianças e realizavam os atendimentos, de forma supervisionada. Nesta etapa, foram realizadas as gravações das interações da criança com SD e seus terapeutas, a partir da colocação de uma máquina filmadora nas salas onde os atendimentos ocorriam. Ao todo, ocorreram 21 sessões terapêuticas ao longo de um ano na extensão universitária;

- Reavaliação - ao término do processo terapêutico analisado, a criança foi reavaliada para investigar os benefícios promovidos pela terapia fonoaudiológica e o desenvolvimento dos sujeitos.

\footnotetext{
A avaliação e reavaliação da criança foi realizada a partir do PROC Protocolo de Observação Comportamental. Ele analisa as habilidades comunicativas, o desenvolvimento cognitivo, a compreensão da linguagem e as produções linguísticas da criança. Esse instrumento foi escolhido por se alicerçar em estudos psicolinguísticos e por possibilitar a avaliação da criança com alterações no desenvolvimento da linguagem através de observações do fonoaudiólogo da interação infantil, mesmo antes do aparecimento formal da oralidade (ZORZI; HAGE, 2004). Além disso, foram pesquisados escores de referência para a avaliação da linguagem de crianças com o desenvolvimento típico, o que é interessante em contexto clínico, pois permite a comparação dos resultados obtidos por sujeitos com distúrbios (HAGE; PEREIRA; ZORZI, 2012).
} 
Os vídeos das sessões de terapia foram transferidos para o programa ELAN (EUDICO Linguistic Annotator), ferramenta criada no Max Planck Institute for Psycholinguistics, Nijmegen - Holanda, que permite a transcrição e análise dos dados. Durante a análise dos vídeos, foram criadas quatro trilhas de observação da filmagem: as produções vocais, as produções gestuais, a matriz linguística (mescla das anteriores) e a atenção conjunta. Ressalta-se que este artigo contempla um recorte dos dados obtidos na coleta e análise dos dados, no qual foi adotada uma abordagem quantitativa, a partir da classificação e quantificação das produções da criança com SD.

Os dados quantitativos referentes à idade, atenção conjunta, matriz linguística e produções vocais e gestuais da criança foram tabulados em uma planilha eletrônica digital e foi realizada uma análise estatística com o teste de Correlação de Pearson para correlacionar essas variáveis.

O nível de significância adotado foi o $\mathrm{p}$-valor $\leq 5 \%$ para todas as análises. O software utilizado foi o R, sendo este gratuito e um dos mais utilizados pela comunidade estatística.

\section{Resultados}

É possível observar o desenvolvimento da criança pesquisada através da avaliação pré e pós intervenção fonoaudiológica, em todos os parâmetros avaliados (Tabela 1).

Tabela 1 - Avaliação da criança com síndrome de Down pré e pós terapia

\begin{tabular}{|c|c|c|c|}
\hline Aspectos observados & $\begin{array}{c}\text { Pontuação } \\
\text { máxima }\end{array}$ & $\begin{array}{c}\text { Pontuação na } \\
\text { avaliação }\end{array}$ & $\begin{array}{c}\text { Pontuação na } \\
\text { reavaliação }\end{array}$ \\
\hline $\begin{array}{c}\text { Habilidades comunicativas } \\
\text { (expressivas) }\end{array}$ & 60 & 10 & 24 \\
\hline $\begin{array}{c}\text { Compreensão da linguagem } \\
\text { oral }\end{array}$ & 40 & 10 & 25 \\
\hline $\begin{array}{c}\text { Aspectos do Desenvolvimento } \\
\text { Cognitivo }\end{array}$ & 50 & 02 & 67 \\
\hline Total da Pontuação & 150 & 22 & \\
\hline
\end{tabular}

Fonte: Elaboração própria 
- Relação entre a matriz linguística multimodal e a atenção conjunta de criança com síndrome de Down

Em relação às habilidades comunicativas, no início das sessões, a criança apresentou pouca intenção de se comunicar com as terapeutas e, nos momentos em que interagiu com elas, produziu balbucios e gestos de apontar. No final do período analisado, o sujeito apresentou mais intenção comunicativa, observada por um uso mais frequente das habilidades dialógicas e das funções comunicativas. Além disso, ele passou a produzir balbucios e jargões, e uma maior variabilidade de gestos representacionais e convencionalizados.

$\mathrm{Na}$ avaliação, a criança respondia não sistematicamente quando era chamada, quando era feita alguma solicitação ou comentário. Já na reavaliação, a criança compreendia ordens com duas ações.

Em relação aos aspectos do desenvolvimento cognitivo, foi observado na avaliação que a criança fazia uso convencional dos objetos, manipulando-os pouco. Além disso, fez imitações de gestos e movimentos visíveis no próprio corpo, mas não foi observada imitação verbal. Na reavaliação, a criança fazia uso convencional dos objetos e conseguia organizá-los em pequenos grupos e explorá-los de modo diversificado. Ela apresentava um maior jogo e esquema simbólico nas atividades, além de realizar imitações de gestos e movimentos visíveis no próprio corpo, e imitações verbais de sílabas e onomatopeias.

Ao analisar os dados, pode-se observar que o número de produções linguísticas da criança aumentou ao longo da intervenção fonoaudiológica. Além disso, a priori, as produções gestuais eram mais frequentes no discurso infantil e, com o avanço da idade e das sessões terapêuticas, houve um aumento das produções vocais e uma maior sincronia entre a quantidade desses dois tipos de produção.

Para exemplificar os dados apresentados acima, foram selecionadas cinco sessões terapêuticas consecutivas da criança pesquisada, no intuito de expor essa dinâmica entre as produções vocais e gestuais (Gráfico 1). 
Gráfico 1 - Matriz linguística multimodal da criança com síndrome de Down ao longo de cinco sessões fonoaudiológicas

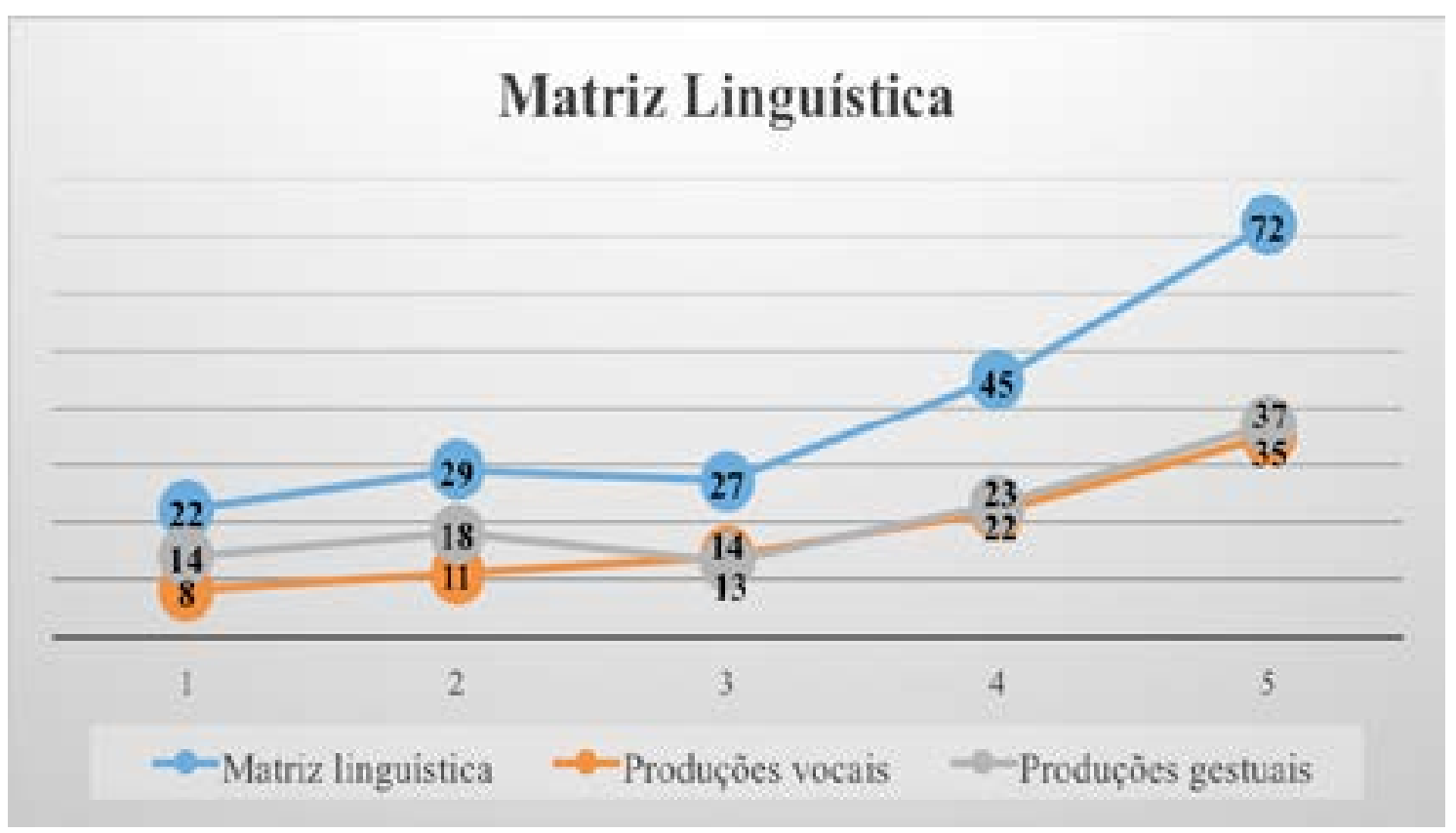

Fonte: Elaboração própria

Verificou-se que houve diferença estatística entre a idade da criança analisada e suas produções vocais, aspecto não observado com as produções gestuais (Tabela 2).

Tabela 2 - Correlação entre a idade e as produções linguísticas da criança

\begin{tabular}{ccc}
\hline Variáveis & Estatística do teste & Valor de $\mathrm{p}$ \\
Produções vocais & 0,888 & $0,04^{*}$ \\
Produções gestuais & 0,733 & 0,16 \\
\hline
\end{tabular}

* Valores significantes $(p \leq 0,05)$ - Teste: Correlação de Pearson

Fonte: Elaboração própria

Em relação à atenção conjunta da criança, foi possível visualizar que o sujeito se inseriu com maior frequência no formato de atenção de verificação. Com o andamento das sessões fonoaudiológicas, houve um aumento da inserção da criança em cenas de atenção de acompanhamento, o que não foi observado com a atenção direta que não 
- Relação entre a matriz linguística multimodal e a atenção conjunta de criança com síndrome de Down

apresentou evolução. Apresentamos os dados de atenção conjunta das mesmas cinco sessões apresentadas anteriormente (Gráfico 2).

Gráfico 2 - Inserção da criança com SD em cenas de atenção das cinco sessões fonoaudiológicas

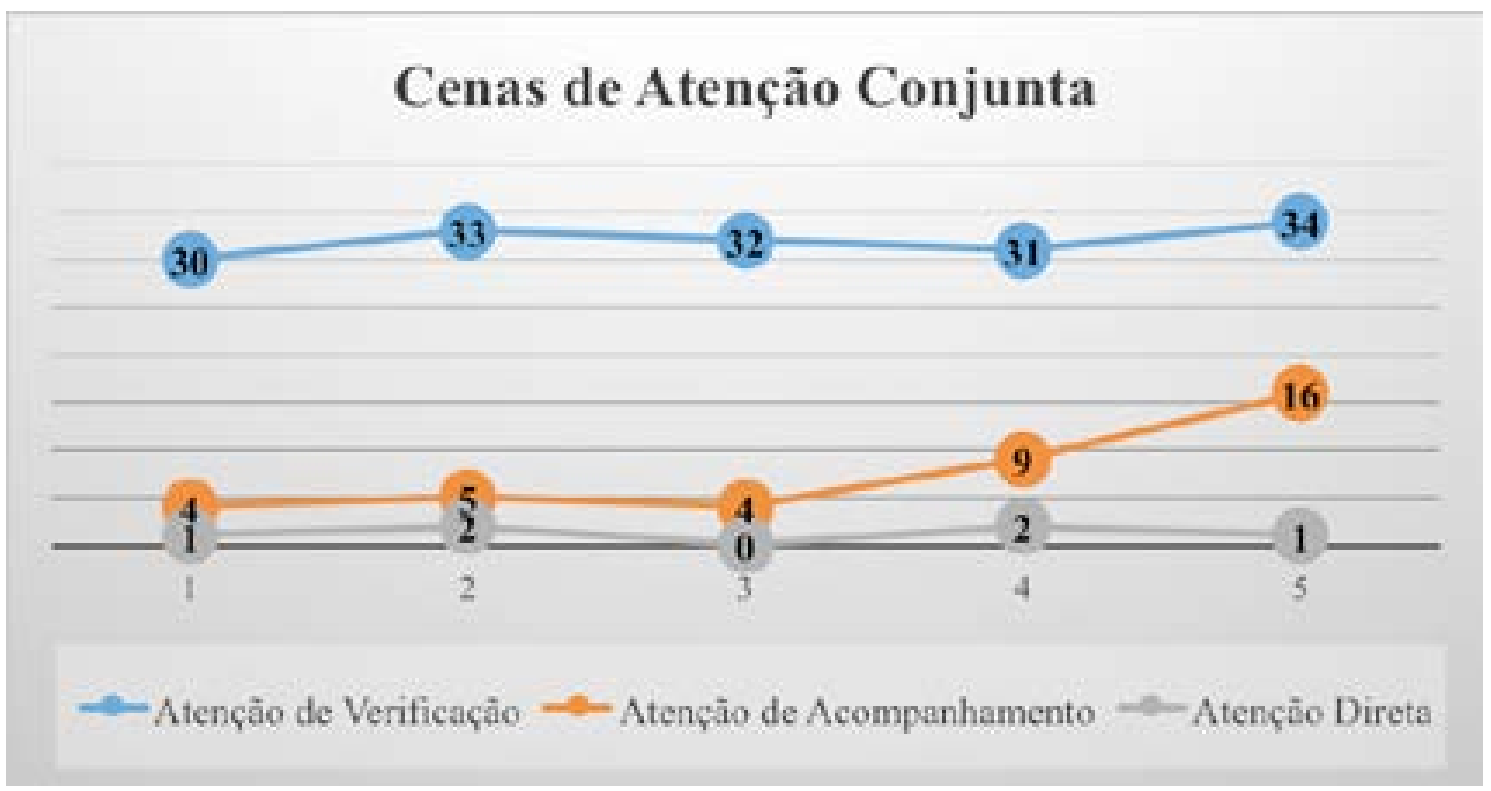

Fonte: Elaboração própria

Ao se correlacionar as produções linguísticas com a atenção conjunta da criança, observou-se diferença estatística entre esta e as produções gestuais do sujeito (Tabela 3).

Tabela 3 - Correlação entre a atenção conjunta e as produções linguísticas da criança

\begin{tabular}{|c|c|c|}
\hline Variável & Estatística do teste & Valor de $\mathrm{p}$ \\
\hline Produções vocais & 0,944 & 0,16 \\
\hline Produções gestuais & 0,990 & $0,001^{*}$ \\
\hline
\end{tabular}

* Valores significantes $(p \leq 0,05)$ - Teste: Correlação de Pearson Fonte: Elaboração própria 


\section{Discussões}

Diante dos resultados obtidos nas avaliações pré e pós-intervenção, constatamos que o processo terapêutico fonoaudiológico foi positivo e favoreceu o desenvolvimento linguístico da criança com síndrome de Down. Contudo, ao se comparar os resultados da avaliação inicial e final (Tabela 1) com os valores esperados para crianças com desenvolvimento típico na mesma faixa etária da criança pesquisada neste estudo, percebe-se que os resultados da criança com SD estão diminuídos, comprovando o atraso nas habilidades avaliadas nessa população (HAGE; PEREIRA; ZORZI, 2012).

Ferreira-Vasques e colaboradoras (2017) apontaram que o desempenho em vocabulário expressivo de crianças com Síndrome de Down foi significativamente inferior quando comparado ao desempenho de crianças com desenvolvimento típico de mesmo gênero e idade cronológica. As autoras indicaram que são previstas, na SD, alterações em atenção, memória, funcionamento simbólico, reconhecimento de regras gramaticais, possibilidade de comportamentos desajustados e habilidades de processamento auditivo e visual, que influenciam diretamente o desenvolvimento lexical e habilidades de comunicação.

Foi observado que houve o aumento das produções vocais com o avanço da idade (Tabela 2), resultado que ressalta a importância da estimulação fonoaudiológica na promoção da plasticidade cerebral e do desenvolvimento da linguagem da criança com síndrome de Down.

O fonoaudiólogo é o profissional responsável por cuidar de todos os aspectos da comunicação humana. A intervenção fonoaudiológica se constitui como um elemento eficaz para a promoção do desenvolvimento da linguagem da criança com SD e, quanto mais precoce essa intervenção for iniciada, maiores as potencialidades do processo terapêutico (LIMA; DELGADO; CAVALCANTE, 2017). Os estudos de Andrade e Limongi (2007) e de Barata e Branco (2010) confirmam a importância da atuação fonoaudiológica na síndrome de Down.

Um estudo com crianças com SD observou que, conforme o avanço da idade, houve um aprimoramento da emissão verbal das crianças durante a avaliação da linguagem (LAMÔNICA et al., 2005). Outra pesquisa que avaliou a linguagem de quatro crianças com síndrome de Down após intervenção fonoaudiológica observou que todos os sujeitos apresentavam, inicialmente, um maior uso da comunicação gestual e, após a terapia, a linguagem de metade das crianças foi classificada como linguagem oral simultânea à comunicação gestual. Além disso, essas duas crianças diminuíram a quantidade de gestos à medida que ampliaram o seu vocabulário (ANDRADE, 2006). 
- Relação entre a matriz linguística multimodal e a atenção conjunta de criança com síndrome de Down

Pode-se esperar, então, que as crianças com síndrome de Down diminuam a predominância de gestos em sua matriz linguística com o avanço de suas idades, com uma estimulação fonoaudiológica efetiva e com o uso de mais produções vocais. Isto indica que a criança encontrou um maior equilíbrio entre os tipos de produção para interagir com o outro, o que justifica a não correlação observada em nosso estudo da idade da criança com as produções gestuais (Tabela 2).

Além disso, é essencial a participação ativa da família em todo o processo terapêutico, visto que ela pode desempenhar um papel tanto de impulsionadora como de inibidora do desenvolvimento do indivíduo. Por isso, é importante que ela ofereça subsídios para que a linguagem infantil se desenvolva de forma efetiva, como: interagir com a criança; permitir que ela interaja com diferentes objetos, ambiente e interlocutores; utilizar uma linguagem dirigida à criança que atraia sua atenção e facilite sua participação na atividade dialógica, entre outros.

Já em relação à atenção conjunta, ressalta-se que ela é fundamental para o desenvolvimento das produções iniciais infantis. Quando as crianças são inseridas em contextos interacionais com o adulto, elas são levadas a interagir com o outro a todo o momento, possibilitando seu desenvolvimento a partir das trocas interativas (LIMA, 2015).

Então, observa-se que, conforme as produções gestuais da criança aumentavam, mais ela se inseria em cenas de atenção conjunta (Tabela 3). Esse resultado é interessante porque mostra que a criança com síndrome de Down - mesmo com atraso no desenvolvimento da linguagem oral - ajusta sua matriz linguística para conseguir se inserir em cenas de atenção conjunta, utilizando, principalmente, as produções gestuais.

Destaca-se que a criança analisada neste estudo realizava apenas dois tipos de produção vocal (balbucios e jargões). Por isso, espera-se que seja possível observar uma correlação entre a atenção conjunta e as produções vocais na SD, quando estas se aprimorarem.

Essa informação é confirmada por um estudo que investigou a relação entre a atenção conjunta e o desenvolvimento lexical na SD e seus resultados apontaram a existência de interferência simultânea e longitudinal entre estes dois aspectos (ZAMPINI; SALVI; D'ODORICO, 2015).

Outra pesquisa evidenciou o papel dos gestos na atenção conjunta e constatou que o uso de palavras dêiticas pode representar um desafio especial para crianças com síndrome de Down durante o desenvolvimento infantil, devido à relação dessas palavras com seus referentes. Na maioria das palavras de representação, é possível estabelecer 
um mapeamento um-para-um entre determinado vocábulo e seu referente, sendo esse susceptível a variações de acordo com o contexto. As palavras dêiticas são diferentes porque não têm referências fixas e seu significado é inteiramente dependente do contexto e pode mudar constantemente durante a interação (IVERSON; LONGOBARDI; CASELLI, 2003).

O que favorece a referenciação, nesse contexto, é a ligação da palavra dêitica com o uso do gesto de apontar para o referente, tornando-o mais concreto. O gesto está fisicamente ligado ao referente (quer através de informações auditivas, contato visual e/ ou orientação) e, desde que seja mantido, serve como um lembrete da identidade do referente. A relação entre as palavras dêiticas e seus referentes, em contraste, é altamente efêmera e abstrata (ou seja, não existe qualquer ligação física entre palavra e referente), e por causa disso, crianças com síndrome de Down podem exigir mais tempo para dominar esta relação antes de palavras dêiticas começarem a emergir (FRANCO; WISHART, 1995; IVERSON; LONGOBARDI; CASELLI, 2003).

Ou seja, antes que as palavras dêiticas emerjam na matriz linguística da criança, os gestos, principalmente o apontar, favorecem a referenciação. Esse gesto parece exercer um papel equivalente ao de produções verbais com caráter referencial, já que tanto o apontar se associa a tais produções, quanto cumprem, na ausência do verbal, a função referencial. Além disso, o apontar contribui para o direcionamento do olhar do parceiro da interação para um objeto que se torne foco de uma cena de atenção conjunta, quando são utilizados por um dos interlocutores para destacar o foco do olhar compartilhado (COSTA FILHO; CAVALCANTE, 2013).

Desse modo, ressalta-se que os gestos demonstram relevância à intervenção terapêutica em linguagem oral nas crianças com SD, tendo em vista que essas produções apresentam um valor preditivo para o desenvolvimento lexical e parecem constituir um meio para o aprendizado de novos significados. Além disso, favoreceriam a atenção conjunta, na medida em que eliciam produções verbais dos adultos, referentes ao objeto foco da atenção da criança; e desempenhariam função social, na medida em que sinalizam ao interlocutor que a criança está preparada para receber determinado tipo de input linguístico (FLABIANO-ALMEIDA; LIMONGI, 2010).

Os gestos, então, realçam o desenvolvimento da linguagem oral, não o dificultam. As produções gestuais possuem várias funções, incluindo as de constituir um importante modo de comunicação, de compensação, de transição, de compartilhar habilidades simbólicas e associação às produções vocais. Na prática clínica, os gestos podem desempenhar um papel valioso no diagnóstico, prognóstico, seleção de metas e intervenção para as crianças com distúrbio de linguagem (CAPONE; MCGREGOR, 2004). 
- Relação entre a matriz linguística multimodal e a atenção conjunta de criança com síndrome de Down

\section{Conclusão}

Neste estudo, com o avanço da idade e da intervenção fonoaudiológica, houve um aumento das produções linguísticas da criança com síndrome de Down, bem como de sua inserção em cenas de atenção conjunta. Além disso, verificou-se que o predomínio dos gestos no discurso infantil diminuiu, enquanto as produções vocais aumentaram.

Contudo, os gestos não devem ser desestimulados durante a intervenção fonoaudiológica, nem durante a interação mãe-bebê, visto que estes favoreciam a entrada da criança em cenas de atenção conjunta e a referenciação que, consequentemente, fomentam a interação com seu interlocutor e o aprimoramento de suas produções.

\section{Referências}

ANDRADE, R. V. A emergência da expressão comunicativa na criança com síndrome de Down. 2006. 258 f. Tese (Doutorado em Ciências) - Faculdade de Medicina, Universidade de São Paulo, São Paulo, 2006.

ANDRADE, R. V.; LIMONGI, S. C. O. A emergência da comunicação expressiva na criança com síndrome de Down. Pró-Fono Revista de Atualização Científica, Barueri, v. 19, n. 4, p. 387-392, 2007.

ÁVILA-NÓBREGA, P. V. Dialogia mãe-bebê: a emergência do envelope multimodal em contextos de atenção conjunta. 2010. 168 f. Dissertação (Mestrado em Linguística) Universidade Federal da Paraíba, João Pessoa, 2010.

BARATA, L. F.; BRANCO, A. Os distúrbios fonoarticulatórios na síndrome de Down e a intervenção precoce. Revista CEFAC, São Paulo, v. 12, n. 1, p. 134-139, 2010.

CAPONE, N. C.; MCGREGOR, K. K. Gesture development: a review for clinical and research practices. Journal of Speech, Language, and Hearing Research, v. 47, p. 173-186, 2004.

COSTA FILHO, J. M. S.; CAVALCANTE, M. C. B. Atenção Conjunta e referência linguística em contextos interativos com um desenho animado. Signo, Santa Cruz do Sul, v. 38, n. 65, p. 143-163, 2013.

FERREIRA-VASQUES, A. T.; ABRAMIDES, D. V. M.; LAMÔNICA, D. A. C. Mental age in the evaluation of the expressive vocabulary of children with Down syndrome. Revista CEFAC, São Paulo, v. 19, n. 2, p. 253-259, 2017. 
FLABIANO-ALMEIDA, F. C.; LIMONGI, S. C. O. O papel dos gestos no desenvolvimento da linguagem oral de crianças com desenvolvimento típico e crianças com síndrome de Down. Revista da Sociedade Brasileira de Fonoaudiologia, São Paulo, v. 15, n. 3, p. 45864, 2010.

FRANCO, F.; WISHART, J. G. Use of pointing and other gestures by young children with Down syndrome. American Journal on Mental Retardation, v. 100, n. 2, p. 160-182, 1995.

FREIRE, R. C. L. et al. Aspectos neurodesenvolvimentais e relacionais do bebê com Síndrome de Down. Avances en Psicología Latinoamericana, Bogotá, v. 32, n. 2, p. 247259, 2014.

HAGE, S. R. V.; PEREIRA, T. C.; ZORZI, J. L. Protocolo de Observação Comportamental - PROC: valores de referência para uma análise quantitativa. Revista CEFAC, São Paulo, v. 14, n. 4, p. 677-690, 2012.

IVERSON, J. M.; LONGOBARDI, E.; CASELLI, C. Relationship between gestures and words in children with Down's syndrome and typically developing children in the early stages of communicative development. International Journal of Language and Communication Disorders, v. 38, n. 2, p. 179-197, 2003.

LAMÔNICA, D. A. C. et al. Avaliação do processo receptivo: investigação do desenvolvimento semântico em indivíduos com síndrome de Down. Revista Brasileira de Educação Especial, Marília, v. 11, n. 1, p. 81-96, 2005.

LAWS, G.; BISHOP, B. V. M. Pragmatic language impairment and social deficits in Williams syndrome: a comparison with Down's syndrome and specific language impairment. International Journal of Language and Communication Disorders, v. 39, n. 1, p. 45-64, 2004.

LIMA, I. L. B.; CAVALCANTE, M. C. B. Desenvolvimento da linguagem na clínica fonoaudiológica em uma perspectiva multimodal. Revista do Gel, São Paulo, v. 12, n. 2, p. 89-111, 2015.

LIMA, I. L. B.; DELGADO, I. C.; CAVALCANTE, M. C. B. Language development in Down syndrome: literature analysis. Distúrbios da Comunicação, São Paulo, v. 29, n. 2, p. 354364, 2017. 
- Relação entre a matriz linguística multimodal e a atenção conjunta de criança com síndrome de Down

LIMA, K. A. Estudo comparativo do uso do apontar e sua relação com a produção vocal infantil, em cenas de atenção conjunta. 2015. 99 f. Dissertação (Mestrado em Linguística) - Universidade Federal da Paraíba, João Pessoa, 2015.

LIMONGI, S. C. O. A Linguagem na Síndrome de Down. In: FERNANDES, F. D. M.; MENDES, B. C. A.; NAVAS, A. L. P. G. P. (Org.). Tratado de Fonoaudiologia. 2. ed. São Paulo: Roca, 2010. p. 373-380.

MCNEILL, D. So you think gestures are nonverbal? Psychological Review, v. 92, n. 3, p. 350-371, 1985.

PORTO-CUNHA, E.; LIMONGI, S. C. O. Modo comunicativo utilizado por crianças com síndrome de Down. Pró-Fono Revista de Atualização Científica, Barueri (SP), v. 20, n. 4, p. 243-248, 2008.

SCHWARTZMAN, J. S. Síndrome de Down. São Paulo: Memnon, 2003.

SILVA, M. F. M. C.; KLEINHANS, A. C. S. Processos cognitivos e plasticidade cerebral na Síndrome de Down. Revista Brasileira de Educação Especial, Marília, v. 12, n. 1, p. 123-138, 2006.

TOMASELLO, M. Origens culturais do conhecimento humano. São Paulo: Martins Fontes, 2003.

ZAMPINI, L.; SALVI, A.; D'ODORICO, L. Joint attention behaviours and vocabular development in children with Down syndrome. Journal of intellectual disability research, v. 59, n. 10, p. 891-901, 2015.

ZORZI, J. L.; HAGE, S. R. V. PROC: Protocolo de Observação Comportamental: avaliação de linguagem e aspectos cognitivos infantis. São José dos Campos: Pulso Editorial, 2004. 
COMO CITAR ESTE ARTIGO: LIMA, Ivonaldo Leidson Barbosa; DELGADO, Isabelle Cahino; CAVALCANTE, Marianne Carvalho Bezerra. Relação entre a matriz linguística multimodal e a atenção conjunta de criança com síndrome de Down. Revista do GEL, v. 15, n. 1, p. 85-99, 2018. Disponível em: https://revistadogel.gel.org.br/.

DOI: http://dx.doi.org/10.21165/gel.v15i1.1835

Submetido em: 02/05/2017. | Aceito em: 27/03/2018. 